\section{Anthropometrically-Based Surgical Technique for Tessier 3 Cleft Reconstruction}

\author{
Aaron L. Morgan, MD, Roger Cason, BS, \\ and Christian A. El Amm, MD
}

\begin{abstract}
Craniofacial clefts are rare entities, with an incidence reported as 1.43 to 4.85 per 100,000 births. The Tessier number 3 cleft, the most medial of the oblique clefts, can manifest as clefting of the lip between the canine and lateral incisors, colobomas of the nasal ala and lower eyelid, and inferior displacement of the medial canthus-frequently disrupting the lacrimal system with extreme variability in expressivity (Eppley).

Literature on cleft lip repair is extensive and has evolved to incorporate anthropometric techniques, based on identifiable landmarks and anthropometric measurements that are compared with contralateral unaffected anatomy or population means and tracked over time to assess impact on growth. Recent focus has been placed on "subunit" repair that repairs "like with like." These approaches have resulted in a remarkable reproducibility of methods and outcomes

Facial cleft surgery publications are sparse due to the rarity of the disorders, and consensus has yet to develop on standardized landmarks, reference measurements, and principles of repair. The authors describe a method of correcting incomplete unilateral Tessier 3 cleft based on the principles described above. Intraoperative photographs, including secondary revisions, as well as immediate and long-term postoperative results are presented.
\end{abstract}

Key Words: Anthropometric, craniofacial, tessier 3, tessier cleft

C raniofacial clefts are rare entities, with an incidence reported as 1.43 to 4.85 per 100,000 births. ${ }^{1}$ The Tessier number 3 cleft, the most medial of the oblique clefts, can manifest as clefting of the lip between the canine and lateral incisors, colobomas of the nasal ala and lower eyelid, and inferior displacement of the medial canthus - frequently disrupting the lacrimal system with extreme variability in expressivity (Eppley).

Literature on cleft lip repair is extensive and has evolved to incorporate anthropometric techniques, based on identifiable landmarks and anthropometric measurements that are compared with contralateral unaffected anatomy or population means and tracked over time to assess impact on growth. Recent focus has been placed on "subunit" repair that repairs "like with like." These approaches

From the Division of Plastic Surgery, Department of Surgery, University of Oklahoma Health Sciences Center, Oklahoma City, OK.

Received January 4, 2016.

Accepted for publication July 28, 2016.

Address correspondence and reprint requests to Christian A. El Amm, MD,

Division of Plastic Surgery, University of Oklahoma Health Sciences

Center, 825 NE 10th Street, Suite 1G, Oklahoma City, OK 73104;

E-mail: Aaron-morgan@ouhsc.edu

The authors report no conflicts of interest.

Copyright $\odot 2016$ by Mutaz B. Habal, MD

ISSN: $1049-2275$

DOI: $10.1097 /$ SCS.0000000000003129 have resulted in a remarkable reproducibility of methods and outcomes.

Facial cleft surgery publications are sparse due to the rarity of the disorders, and consensus has yet to develop on standardized landmarks, reference measurements, and principles of repair. We describe a method of correcting incomplete unilateral Tessier $3 \mathrm{cleft}$ based on the principles described above. Intraoperative photographs, including secondary revisions, as well as immediate and long-term postoperative results are presented.

\section{SURGICAL TECHNIQUE}

\section{Markings}

Two key landmarks, endocanthion (medial canthus) and alare (lateral ala insertion), ${ }^{2}$ are marked on the noncleft side. The facial midline plane is identified using the best available midline identifiers such as chin point, lower lip and gingival midlines, and nasion. The ideal location of the endocanthion and alare on the cleft side is identified by symmetrical transposition from the noncleft side relative the midline. Additionally, the nasolabial groove and the eyelid-cheek junction is marked bilaterally (Fig. 1).

Using the transposed alar point, the location of the alar insertion on the affected side is marked to re-create the alar-facial groove. Skin coverage medial to the line is preserved to create a turnover lining flap for the nostril.

The amount of elevation of the medial canthus on the cleft side is measured and the distance between endocanthion-alare (en-al) is measured bilaterally and verified to be identical. On the cleft side, the distance between medial canthus to eyelid-cheek junction is measured, and compared with the noncleft side. The subtracted deficiency in lower eyelid height ("l") is compensated on the cleft side by a hemi-Tripier flap based medially off the upper lid, whose width is set to " 1 ." The rest of the distance deficiency between alare to eyelid-cheek junction ("c") is determined on the noncleft side. Distance " $c$ " is marked on the cleft side lateral cheek advancement flap as a vertical line extending between nasolabial and eyelidcheek junction (Fig. 1A).

The edges of the cleft are incised and refreshed, and grossly dysgenetic tissue is excised. The alar insertion line is incised on the lateral segment and the skin coverage medial to that is elevated based medially to supplement nostril mucosal lining. The residual alar skin and subcutaneous structures on the medial segment are freed off the medial insertion until fully able to rotate and transpose into place. The junction of eyelid to cheek is incised laterally to allow the medial lower eyelid and canthus to elevate supero-medially to position the medial canthus in its ideal location. The edges of the coloboma on the medial canthus are refereshed and the tarsal strip of the lower lid suspended to the medial canthal confluence (Fig. 1B). The medially based hemi-Tripier flap is elevated and transposed to resurface the resultant defect. The mucosal lining turnover flap is transposed (Fig. 1C). A template of the osseous defect obtained directly from the patient's anatomy or from preoperative imaging is made (Fig. 2). A $4 \mathrm{~cm}$ parietal scalp incision is done and a cranial bone graft is harvested to the desired template. The bone graft is secured to the edges of the cleft. A cheek advancement flap is elevated full-thickness and advanced into the defect until line "c" aligns with the endocanthion-alare axis, thus providing full subunit correction of the defects. The flaps are secured in place, and final tailoring completed (Fig. 1D).

The early and late clinical and radiographic results are shown in Figures 2 and 3 , respectively. A mild relapse of the medial canthal position was noted postoperatively, and was observed to worsen after dacryocystorhinostomy, which raises questions about timing 

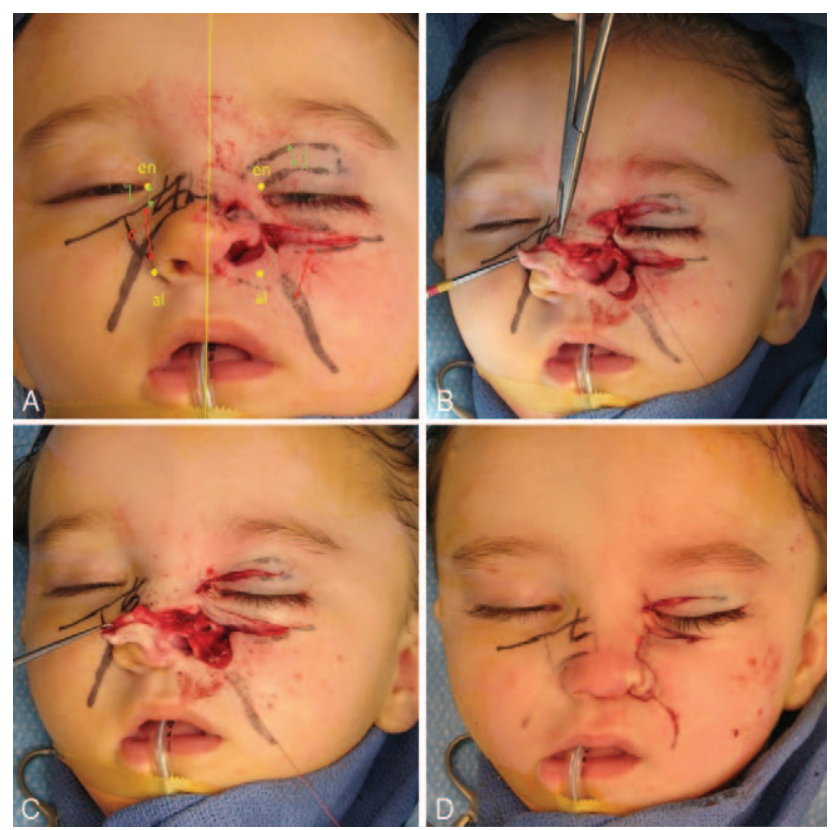

FIGURE 1. Operative markings and technique. (A) Operative markings: endocanthion (en), medial canthus; Alare (al), lateral alar insertion; lower lid deficiency (I); cheek deficiency (c). (B) Flap elevation and medial canthopexy (C) Transposition of hemi-Tripier flap and mucosal turnover flap. The bed is ready for bone grafting to the deficient maxillary segments. (D) Cranial bone graft secured with overlying cheek myocutaneous flap advancement and inset. Caudal repositioning of ala with definition of alar facial groove.

and sequencing the dacryocystorhinostomy relative to the definitive repair. A repeat medial canthopexy using a retrocaruncular approach was done at age 5 after completion of the rapid phase of interorbital growth and prior to schooling. A small Z-plasty to define the alar-facial groove and an auricular composite graft to reconstruct the soft triangle were also required.

\section{DISCUSSION}

Tessier-type craniofacial clefts are rare, and the number 3 cleft is one of the more infrequently seen clefting patterns. ${ }^{1,3,4}$ Most arise sporadically and are thought to involve failure of fusion between the medial nasal prominence and the maxillary and lateral nasal processes. $^{1,4,5}$ This cleft extends from the nasal ala to the medial canthus, and variably involves skin and soft tissue, cartilage, bone, and mucosa. Incomplete clefts are restricted to disruption of the lateral nasal and maxillary processes, resulting in sparing of the lip. ${ }^{5}$ Because of this variability, thorough preoperative physical examination and proper imaging are critical to appropriate surgical management.

Owing to the rarity and variable presentation, few reconstructive guidelines have been presented. General surgical options, including multiple local flaps with or without tissue expansion, for complex Tessier 3 clefts in combination with a multitude of other craniofacial anomalies are usually presented as case reports or small series. ${ }^{6-13}$ While most report some degree of long-term follow-up, there is often little description of secondary procedures and no standardized discussion of topographic landmarks or reproducible measurements to develop a standardized approach to management. A reconstructive algorithm based on soft tissue and bony involvement has been proposed. ${ }^{14}$ Other clinical reports involving unilateral, incomplete clefts have good results over the documented time of follow-up, ${ }^{15,16}$ but have similar criticisms as the above.

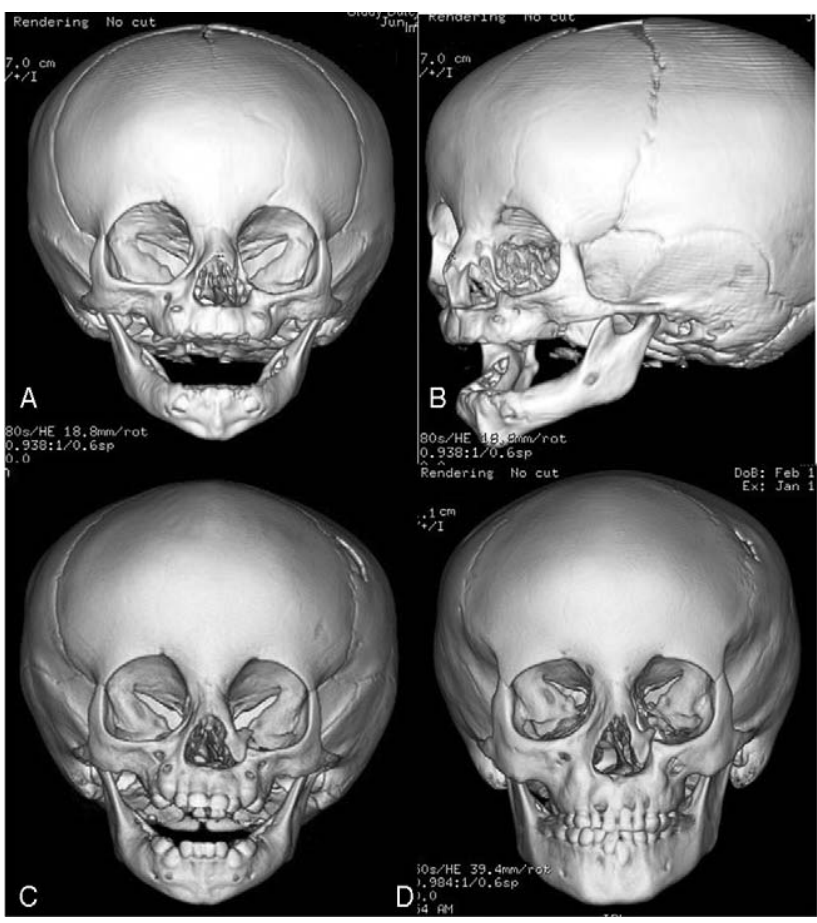

FIGURE 2. Volumetric computed tomography scan reconstructions. (A) Preoperative AP view. Note absence of frontal process of maxilla and medial orbital wall/inferior orbital rim. (B) Preoperative oblique view. (C) One year postoperative. Note incorporation of bone graft into bony orbit but persistence of maxillary osseous cleft. (D) Six years postoperative. Note continued growth of the grafted nasal sidewall/maxilla.

In our patient, a combination of a hemi-Tripier and a cheek advancement flap was used to recreate the deficient soft tissues, providing "like tissues with like tissues" emphasized by a "subunit" approach. We utilized contralateral reproducible distances "l" and "c" based on external landmarks to guide the operation: from the medial canthus to eyelid-cheek junction and from the eyelid-cheek junction to base of the alar-facial groove. These can
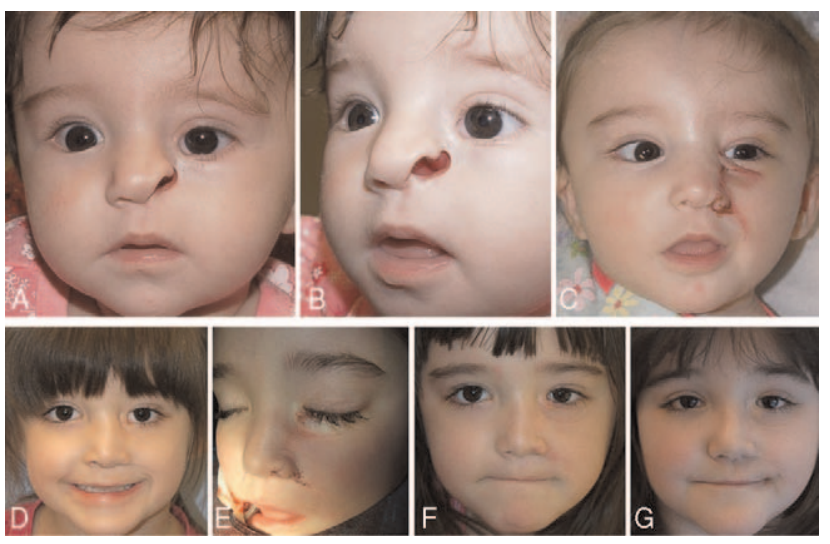

FIGURE 3. Clinical photographs. (A) Preoperative AP view. (B) Preoperative oblique view. (C) One week postoperative result. (D) Patient at age 4 . Note visible scar from dacryocystorhinostomy and relapse of the medial canthus malposition and coloboma. (E) Intraoperative view of secondary canthal reconstruction, alar Z-plasty and soft triangle reconstruction. (F) Immediate postoperative result after revision. (G) Late results age 8 . Note harmonious growth of maxillary elements, nasal sidewall, and absence of medial cheek flatness. 
then be used to guide markings for the hemi-Tripier and cheek advancement flaps, respectively. This allows for improved replication and symmetry, which can still be individualized based on the severity of tissue deficiency.

This approach is ideally suited to unilateral, isolated clefts, as intact anatomy on the contralateral side is required for the corresponding measurements. Alternatively, anthropometric published references can be used for bilateral patients. ${ }^{17}$ The patient had an acceptable long-term outcome with a follow-up of nearly 8 years. Discussion and documentation throughout the patient's course are presented, including 2 minor revisionary surgeries secondary to late cicatricial scar contracture. Revisions are felt to be inevitable and speak to the difficulty of reconstruction and importance of reconstruction of all involved tissues, especially mucosal coverage.

We present a patient with a good long-term postoperative result based on anthropometric methods to reconstruction. We feel this initial technique along with documentation of subsequent procedures can help provide a more reproducible form of reconstruction of the soft tissues in this rare patient population.

\section{REFERENCES}

1. Kawamoto HK Jr. The kaleidoscopic world of rare craniofacial clefts: order out of chaos (Tessier classification). Clin Plast Surg 1976;3:529572

2. Farkas LG, Posnick JC. Growth and development of regional units in the head and face based on anthropometric measurements. Cleft Palate Craniofac J 1992;29:301-329

3. Tessier P. Anatomical classification facial, cranio-facial and laterofacial clefts. J Maxillofac Surg 1976;4:69-92

4. Eppley BL, van Aalst JA, Robey A, et al. The spectrum of orofacial clefting. Plast Reconstr Surg 2005;115:101e-114e

5. Shewmake KB, Kawamoto HK Jr. Congenital clefts of the nose: principles of surgical management. Cleft Palate Craniofac $J$ 1992;29:531-539

6. Monasterio FO, Fuente del Campo A, Dimopulos A. Nasal clefts. Ann Plast Surg 1987;18:377-397

7. Monasterio FO, Taylor JA. Major craniofacial clefts: case series and treatment philosophy. Plast Reconstr Surg 2008;122:534-543

8. Van der Meulen JC. Oblique facial clefts: pathology, etiology, and reconstruction. Plast Reconstr Surg 1985;76:212-224

9. Allam KA, Lim AA, Elsherbiny A, et al. The Tessier number 3 cleft: a report of 10 cases and review of literature. J Plast Reconstr Aesthet Surg 2014;67:1055-1062

10. da Silva Freitas R, Alonso N, Busato L, et al. Oral-nasal-ocular cleft: the greatest challenge among the rare clefts. J Craniofac Surg 2010;21:390395

11. Menard RM, Moore MH, David DJ. Tissue expansion in the reconstruction of Tessier craniofacial clefts: a series of 17 patients. Plast Reconstr Surg 1999;103:779-786

12. Toth BA, Glafkides MC, Wandel A. The role of tissue expansion in the treatment of atypical facial clefting. Plast Reconstr Surg 1990;86:119122

13. Chen PK, Chang FC, Chan FC, et al. Repair of Tessier no. 3 and no. 4 craniofacial clefts with facial unit and muscle repositioning by midface rotation advancement without Z-plasties. Plast Reconstr Surg 2012;129:1337-1344

14. Mishra RK, Purwar R. Formatting the surgical management of Tessier cleft types 3 and 4. Indian J Plast Surg 2009;42 (suppl):S174-S183

15. Cizmeci O, Kuvat SV. Tessier no. 3 incomplete cleft reconstruction with alar transposition and irregular z-plasty. Plast Surg Int 2011;2011:596569

16. Reddy SG, Reddy RR, Obwegeser J, et al. Options for the nasal repair of non-syndromic unilateral Tessier no. 2 and 3 facial clefts. Indian J Plast Surg 2014;47:340-345

17. Farkas LG, Katic MJ, Forrest CR, et al. International anthropometric study of facial morphology in various ethnic groups/races. J Craniofac Surg 2005;16:615-646
The Role of Conservative Management in Pneumosinus Dilatans Frontalis With Minimal Bony Deformity

\author{
Ilyes Berania, MD, ${ }^{*}$ Sam J. Daniel, MD, MSc, ${ }^{\dagger}$ \\ Gaby Doumit, MD, MSc, ${ }^{\ddagger}$ Ramy Kafrouni, BSc, \\ and Marie-Claude Quintal, MD*
}

\begin{abstract}
The authors describe the conservative management of 2 rare patients of uncomplicated pneumosinus dilatans of the frontal sinus with minimal bossing of the forehead. Regular nasal hygiene in combination with topical corticosteroids was administered with following complete resolution symptoms.
\end{abstract}

Key Words: Frontal sinus, paranasal sinuses, pneumonsinus dilatans

$T^{\mathrm{h}}$ he forehead is a central component of the facial skeleton allowing to differentiate male from the female features. ${ }^{1}$ In addition, the upper-third of the face has a critical role in our esthetic perception of attractiveness. ${ }^{2}$ Over the past decades, frontal bone remodeling has indisputably been addressed in cosmetic craniofacial surgery, notably in gender-reassignment surgery. ${ }^{3}$

Several conditions have been associated with frontal bossing, including Pneumosinus dilatans (PSD), which is a rare disease affecting the paranasal sinuses. It is considered a benign condition for the majority of patients. Pneumosinus dilatans is defined an abnormal expansion of an aerated sinus extending beyond normal wall margins, while preserving mucosa integrity and bony wall thickness. Pneumatocoele can be distinguished from the PSD by its invasive characteristics leading to bone thinning and/or erosion. The differential diagnosis includes a hypersinus, which refers to an increased size of a sinus cavity while remaining within normal bony margins. ${ }^{4}$ Pneumosinus dilatans was initially reported in 1898 by Meyes et $\mathrm{al}^{5}$ and less than a 100 patients have been described so far. ${ }^{6}$ The frontal sinus seems to be the most affected paranasal sinus, followed by the ethmoid, sphenoid, and maxillary respectively. ${ }^{7}$ Pneumosinus dilatans is an uncommon finding in the pediatric population.

Various surgical modalities have been previously described to correct the bony deformity involving the frontal bone, and to relieve the obstructive effect possibly observed in PSD. Functional endoscopic sinus surgery and bone reshaping surgery through the use of a bicoronal incision are commonly used approaches associated with satisfactory functional and morphological results. ${ }^{4}$

From the *Pediatric Otolaryngology - Head \& Neck Surgery Department, Sainte-Justine Hospital; †Pediatric Otolaryngology - Head \& Neck Surgery Department, Children’s Hospital; and †Pediatric Plastic Surgery Department, Sainte-Justine Hospital, Montreal, Canada.

Received March 12, 2016.

Accepted for publication July 28, 2016.

Address correspondence and reprint requests to Ilyes Berania, MD, 3175

Côte Ste-Catherine Road, Montreal, Quebec H3T1C5, Canada;

E-mail: ilyes.berania.n@gmail.com

The authors report no conflicts of interest.

Copyright $\odot 2016$ by Mutaz B. Habal, MD

ISSN: $1049-2275$

DOI: $10.1097 /$ SCS.000000000003130 